\title{
Ferran Canyameres. La trayectoria intelectual de un escritor catalán
} en el exilio francés

Jaume Aulet

\section{Citer ce document / Cite this document :}

Aulet Jaume. Ferran Canyameres. La trayectoria intelectual de un escritor catalán en el exilio francés. In: Exils et migrations ibériques au XXe siècle, ${ }^{\circ} 6,1999.60$ ans d'exil républicain : des écrivains espagnols entre mémoire et oubli. pp. 227-247; doi : https://doi.org/10.3406/emixx.1999.1015

https://www.persee.fr/doc/emixx_1245-2300_1999_num_2_6_1015

Fichier pdf généré le 28/08/2018 


\title{
Ferran Canyameres. La trayectoria intelectual de un escritor catalán en el exilio francés
}

\author{
Jaume Aulet \\ Universitat Autònoma de Barcelona
}

\section{Literatura y autobiografia ${ }^{1}$}

Ferran Canyameres (Terrassa, 1898 - Barcelona, 1964) fue un auténtico hombre de letras : un escritor que, además de hacer incursiones en todos los géneros literarios, se dedicó también a la traducción, el periodismo, la edición y a un gran número de actividades relacionadas con el mundo de la literatura. En el prólogo a Migtemps (1950), el primer libro de poesía publicado por Canyameres, Joan Oliver ya lo describe como una persona muy activa y remarca la imagen "de mercader o missioner internacional $i$ de suscitador $i$ animador d'empreses $i$ aventures" ["de mercader o misionero internacional y de suscitador y animador de empresas y aventuras ${ }^{2}$ "]. Albert Manent resume perfectamente este talante en las dos palabras que sintetizan el retrato que dedica al autor catalán y que son tan exactas que prácticamente

${ }^{1}$ Una primera versión en lengua catalana de este artículo apareció en 1998 en la revista local Ciutat: Jaume AULET, "Ferran Canyameres i l'exili francès", Ciutat, Terrassa, 7 (primavera 1998), p. 14-21.

2 Joan OLIVER, "Pròleg" a Ferran CANYAMERES, Migtemps, en Obra completa (volumen III), Barcelona, Columna, 1993, p. 6. La idea queda complementada en esta otra cita del mismo prólogo: "Les empreses, a les seves mans, es tornen dòcils, com enamorades que se li lliuressin. I amb una nota particular: en ell diria que s'acompleix el maridatge insòlit de l'home de programes utilitaris immediats amb l'idealista imprudent i pròdig" ["Las empresas, en sus manos, se vuelven dóciles, como amantes que se le entregasen. Y con una nota particular: en él diría que se cumple el maridaje insólito del hombre de programas utilitarios inmediatos con el idealista imprudente y pródigo] (ibid., p. 5). Por exigencias de edición y para facilitar la lectura, todas las citas en catalán incluídas en el artículo aparecen también traducidas al español. 
no admiten ni traducción: el "vitalisme lletraferit". A lo largo de toda la vida, Ferran Canyameres es la viva imagen de este vitalismo tocado y herido por la pasión hacia la literatura. Por este motivo, si queremos tener una visión suficientemente completa de su aportación a las letras catalanas, no hemos de limitarnos tan sólo al estudio de su narrativa, poesía o teatro, sino que debemos adoptar una perspectiva de análisis un poco más amplia, la cual debe prestar atención también a una adecuada valoración de los múltiples aspectos de una trayectoria intelectual enormemente rica y compleja.

Quizás es por este motivo que la parte más interesante de la producción literaria de Canyameres - y seguramente también la de mayor calidad - es la que relaciona lo que es estrictamente literatura con la mencionada trayectoria intelectual. Nos referimos a los dietarios, los libros de memorias o el retrato de personas próximas. La suya es una obra fundamentalmente biográfica y autobiográfica, donde la fuerza de la experiencia vital aflora por todas partes. La vida va ligada a la literatura, pero - sobre todo - la literatura es la que resulta inseparable de la vida ${ }^{4}$. Desde este punto de vista no es extraño que una narración como "L'home que volia patir", escrita a principios de 1942 y publicada veinte años después en Món, dimoni $i$ carn (1962), sea en realidad - pese a que no se explicite en ninguna parte - un retrato minucioso y fidedigno de las peripecias en el exilio parisino de su amigo Sebastià Gasch. La voluntad testimonial queda por encima de las convenciones de género y lo que resulta de ello no sabemos exactamente si debe ser calificado como un cuento, una nouvelle o un relato memorialístico. Este rasgo es aún más apreciable en $E l$ gran sapastre (1977), libro escrito igualmente en Francia a principios de los cuarenta y que puede ser leído como simple

3 Albert MANENT, "Ferran Canyameres, el vitalisme lletraferit", en Solc de les hores. Retrats d'escriptors $i$ de polítics, Barcelona, Destino, 1988, p. 159-168. Reproducido con variantes como prólogo a Ferran CANYAMERES, Obra completa (volumen I), Barcelona, Columna, 1992, p. I-VII. Sobre la biografía de Canyameres - y en espera de la que actualmente está preparando el profesor Gustau Erill - véanse también DIVERSOS AUTORES, Ferran Canyameres, Terrassa, Ajuntament de Terrassa, 1988, ("Homenatges") y Salvador CARDÚS I ROS, "Memòria i relat biogràfic", Ciutat, Terrassa, 7 (primavera 1998), p. 8-13.

${ }^{4}$ La idea queda perfectamente apuntada en Jaume CLOSA, "El gust per la forma i l'emoció", Al Vent, Terrassa, 66 (diciembre 1983), p. 14-16. El artículo se incluye en un monográfico de la revista titulado "Ferran Canyameres, la vigència d'un escriptor oblidat". Véase también Gustau ERILL I PINYOT, "Ferran Canyameres, un escriptor poc conegut i menys valorat", Serra d'Or, 418 (octubre 1994), p. 54-56; i Gustau ERILL I PINYOT, "L'obra completa de Ferran Canyameres", Serra d'Or, 431 (novembre 1995), p. 71-72. 
panfleto, como biografia de Joan Puig i Ferreter, como relato autobiográfico o prácticamente como una novela. Incluso podemos considerar que el interés hacia la figura de Josep Oller - su compatriota y conciudadano, también natural de Terrassa, que fundó en París el célebre Moulin Rouge - es en el fondo una típica proyección en búsqueda de un alter ego, lo cual permite entender en clave literaria la biografia que el escritor le dedica en $1946^{5}$.

En este sentido que hemos visto, Ferran Canyameres es un hombre de letras, pero también un hombre de su tiempo. Su concepción de la literatura es comparable a la de otros escritores contemporáneos suyos como Lluís Capdevila, el mismo Joan Puig i Ferreter y otros ${ }^{6}$. Son gente de formación autodidacta, con una enorme fuerza vital, que se han dedicado durante un periodo de sus respectivas vidas a la bohemia y a la aventura, que no acaban de conectar con los sectores literarios hegemónicos, que a la hora de escribir parten prácticamente siempre de la realidad y especialmente de la experiencia biográfica o autobiográfica - lo cual provoca que entiendan la literatura como una forma de testimonio y a menudo de justificación -, que se ajustan poco a las convenciones de los géneros y tampoco se preocupan excesivamente por las cuestiones técnicas. Hay que tener en cuenta, a pesar de todo, un matiz importante en el caso que nos ocupa : lo que Canyameres no admite en este tipo de literatura es una exaltación del yo que conduzca a una ridícula complacencia egocéntrica ${ }^{7}$.

${ }^{5}$ Ferran CANYAMERES, L'homme de la belle époque (1946), biografía reelaborada después en catalán con el título de Josep Oller i la seva època (1959).

${ }^{6}$ Tampoco es extraño - salvando las distancias - que uno de los literatos en lengua francesa que haya leído sea Henri-Frédéric Amiel, autor de un prolijo Journal intime, escrito a lo largo de toda su vida y de cuyo título deriva el extenso Diari intim que Canyameres publica en 1972.

${ }^{7}$ Éste es precisamente uno de los motivos de la ruptura con Puig i Ferreter, tal y como queda claro en El gran sapastre; o del distanciamiento respecto al tipo de dietario de Amiel, el cual "deixa una amarga impressió, decebedora, àdhuc insuportable" ["deja una amarga impresión, decepcionante e incluso insoportable"] (CANYAMERES, Diari íntim, en Obra completa, volumen IV, Barcelona, Columna, 1994, p. 307). Citamos siempre los textos de Canyameres a partir de la edición de los seis volúmenes de su Obra completa, publicados en Barcelona por la editorial Columna entre 1992 y 1996. 


\section{El exilio francés. París como referente}

En este artículo nos limitamos solamente al análisis de la trayectoria intelectual de Ferran Canyameres durante los años de su exilio francés. Se trata, por lo tanto, de un estudio parcial y modesto. El escritor cruza la frontera en enero de 1939 en compañía de su hijo - la esposa y la hija no se reunirán con ellos hasta abril de 1942 - y regresa a Cataluña de manera definitiva en el verano de 1949. Durante estos diez años se convierte en una pieza clave del exilio literario catalán en Francia, aspecto que no siempre ha sido suficientemente remarcado ni valorado ${ }^{8}$. Hasta hace poco la fuente esencial para conocer la actividad de Canyameres durante estos años era la parte publicada de su diario personal, titulada Diari íntim (1972), la cual está redactada básicamente entre los años 1942 y 1945 . El libro es un dietario vital más que intelectual, pero constituye un material de primera para profundizar en el pensamiento literario del autor y para ir recorriendo el trabajo que va haciendo. Seguramente es ésta la pieza literaria más importante de Canyameres. Tiene momentos auténticamente magistrales, como cuando, después del desembarco de los aliados en Normandía, el texto se convierte en un extraordinario dietario de guerra centrado en la vida cotidiana y en el componente humano de las experiencias vividas (también las de los soldados alemanes en retirada).

${ }^{8}$ Joan Triadú ya lo destaca adecuadamente en 1983 en una entrevista sobre el tema realizada por Ramon Comorera: "Podriem dir que era una mena de cònsul, sense nomenament, dels catalans de Paris" ["Podríamos decir que era una especie de cónsul, sin nombramiento, de los catalanes de París"] (Al Vent, Terrassa, 66, diciembre 1983, p. 23). Véase también Montserrat CANYAMERES I CASALS, "El moviment intel-lectual català a França durant l'exili (1939-1951), a través de l'epistolari de Ferran Canyameres", prólogo a Ferran CANYAMERES, Obra completa, VI: Epistolari (1939-1951), edición de Montserrat Canyameres i Casals, Barcelona, Columna, 1996, p. XI-XVIII; y Joan TRIADÚ, "El centenari d'un escriptor entre l'arrelament i l'aventura", Serra d'Or, 458 (febrero 1998), p. 51-52.

9

El mismo escritor deja claro en un determinado momento del diario que su intención es buscar el equilibrio y no hacer un relato estrictamente intimista. La vida interior tiene un papel importante, pero no quiere que sea exclusivo: "No sé si serà possible de continuar aquest diari. Sentiria que hagués d'interrompre'l. Són molts els que he començat sense continuar durant llarg temps per manca de vida interior. Aquest potser l'hauré d'interrompre per excés" ["No sé si será posible continuar este diario. Me sabría mal tenerlo que interrumpir. Son muchos los que he empezado sin continuarlos durante largo tiempo por falta de vida interior. Este quizá deberé interrumpirlo por exceso"] (CANYAMERES, Diari intim, op. cit., p. 327). 
Recientemente, con la publicación en el último volumen de la obra completa de una selección de la correspondencia de esta época, disponemos de nuevos datos para el estudio del periodo. Se trata de un material enormemente atractivo, que ofrece mucha información de primera mano sobre lo que aquí nos interesa, por lo que pasa a ser un gran complemento del Diari íntim ${ }^{10}$. De hecho, gracias a la publicación de esta correspondencia podemos tener en la actualidad una visión suficientemente completa de la trayectoria intelectual del escritor durante estos años ${ }^{11}$.

No es extraño que en el momento de tomar el camino del exilio Ferran Canyameres escoja París como lugar de residencia. La ciudad había sido desde siempre su punto de referencia, el espacio donde proyectaba, aun siendo muy joven, sus ideales vitalistas. Ya en 1917, cuando con diecinueve años emprende por primera vez la aventura viajera, la ciudad escogida es la capital francesa. No nos debe extrañar si tenemos en cuenta que París era todavía el auténtico centro cultural del mundo occidental. La aventura - con el paso previo por una granja de Carcasona - es comparable a la de otros escritores catalanes de trayectoria similar, como el mismo Puig i Ferreter. En este sentido, tampoco es extraño que su principal contacto en la capital cuando reside en ella por primera vez sea Joan Pérez Jorba, otro de los intelectuales catalanes formados bajo la influencia del vitalismo modernista $^{12}$.

Canyameres había conocido París en guerra y ahora regresa cuando la ciudad está a punto de vivir otra, con ocupación alemana incluída. Exilio, guerra y ocupación no parecen en principio el contexto más adecuado para el

${ }^{10}$ Ferran CANYAMERES, Epistolari, op. cit. Sobre la importancia del volumen - pero también la poca fiabilidad de la edición- - véase Jaume AULET, "Uns quants epistolaris publicats recentment: comentari i reflexió", Els Marges, 57 (diciembre 1996), p. 83-95. Respecto a la existencias de otros materiales aún inéditos, véase Montserrat CANYAMERES I CASALS, Catàleg del contingut de la sala Ferran Canyameres. Casa Alegre de Sagrera, Terrassa, Ajuntament de Terrassa, 1992.

"En la carta de 30 de marzo de 1947 a Pere Mas i Perera, el mismo Canyameres hace una especie de balance de la tarea desempeñada desde 1939. En la edición de la obra completa las cartas están ordenadas cronológicamente, lo cual facilita que no sea necesario ahora remitir constantemente a las páginas del libro para identificar las citas.

${ }^{12}$ Sobre esta primera estancia véase Ferran CANYAMERES, De Paris, el fel i la mel (1965), en Obra completa (volumen I), op. cit., p. 145-318. Para el estudio del tema véase Xavier MARCET, "La ciutat de Ferran Canyameres. Terrassa com a contrapunt", Ciutat, Terrassa, 7 (primavera 1998), p. 4-7. 
desarrollo de la vida cultural. Quizás por eso - también a causa de la violenta ruptura con Puig i Ferreter - Canyameres reside durante unos años en Bouglainval, un pueblecito a pocos kilómetros de la capital. Es evidente que la imagen real del París ocupado se aleja mucho de la idealización de otros tiempos. Bouglainval se convierte así en una especie de refugio individual y moral a la espera de tiempos mejores :

Per fi tornem a Bouglainval. Respiro. Adéu, Paris! Tant de bo no em veiessis més. Tot el que em podies ensenyar ja m'ho sé de memòria. Potser et tornaré a cobejar quan retrobaràs el teu aspecte, quan no pul tularà pels teus carrers la gent àvida de guanyar diners en detriment dels resignats, dels qui sofreixen de la situació ${ }^{13}$.

[Por fin volvemos a Bouglainval. Respiro. Adiós, París ! Ojalá no me vieses más. Todo lo que me podías enseñar ya me lo sé de memoria. Tal vez te volveré a codiciar cuando reencuentres tu aspecto, cuando no pululará por tus calles la gente ávida de ganar dinero en detrimento de los resignados, de los que sufren de la situación.]

Pese a ello, tanto el dietario como el epistolario demuestran que durante este tiempo el auténtico centro de operaciones del escritor continúa siendo la capital. Se desplaza a ella constantemente - incluso en momentos en los que el viaje comporta grave peligro para su integridad física - y despliega en la ciudad numerosas actividades. Bouglainval facilita el recogimiento para la lectura o la escritura y París es no solo el complemento necesario a la hora del activismo cultural, sino también un complemento irrenunciable. Hasta el punto de que, así que los aliados liberan la zona a finales del verano de 1944, el escritor vuelve a fijar la residencia en la capital. Serán momentos a partir de entonces de gran actividad cultural por su parte y de poca producción literaria. Así lo declara en una carta de 20 de mayo de 1945 a Josep PuigArnaus :

D'ençà que he tornat a Paris que ben poca cosa he escrit. S'hi viu amb una agitació embrutidora. Ha minvat la fuga amb la qual escrivia a Bouglainval.

${ }^{13}$ CANYAMERES, Diari intim, op. cit, p. 305 La anotación corresponde al 9 de abril de 1942. 
[Desde que he vuelto a Paris he escrito muy poco. Se vive alli con una agitación embrutecedora. Ha disminuido la euforia con la que escribía en Bouglainval.]

Y lo corrobora, muy gráficamente, unos cuantos días después (el 12 de junio) en carta a Josep M. Lladó :

Paris, sense un raconet intim on poder-se evadir de cap a un llibre o en la febre d'escriure; París amb massa atractiu exterior; París amb vibracions cosmopolites; París el de les mil veus $i$ dels dos mil ressons; París amb pocs gaudis d'estar per casa ; París, immensa finestra que produeix vertigen...

[París, sin un rinconcito íntimo donde poderse evadir en un libro o en la fiebre de escribir ; París con demasiado atractivo exterior ; París con vibraciones cosmopolitas ; París el de las mil voces y las dos mil resonancias; París con pocos goces de trapillo ; París, inmensa ventana que produce vértigo...]

No debe ser casualidad que, mientras reside en Bouglainval, cuando tiene en mente la idea del exilio piense en Terrassa. ${ }^{14}$ En cambio, cuando ya se ha situado de nuevo en París, excluye expresamente esta posibilidad y se decide por Barcelona, que es donde acabará yendo finalmente. Lo afirma claramente en enero de 1948 a su amigo Pere Mas i Perera : "No cal dir que si jo torno a Catalunya no fixaré la meva residència a Terrassa $i$ que procuraré espavilar-me per venir sovint a París" ["No es necesario decir que si yo vuelvo a Cataluña no fijaré mi residencia en Terrassa y que procuraré apañármelas para venir a menudo a París"]. La propuesta se concreta pocos meses más tarde : "Estic mig disposat a tornar allà baix, però a condició de passar a viure a Barcelona" ["Estoy medio dispuesto a volver allí abajo, pero con la condición de pasar a vivir en Barcelona"]. Pese a todo, la capital francesa continúa siendo el referente idílico :

${ }^{14}$ Véase CANYAMERES, Diari intim, op. cit., p. 304. La ciudad de Terrassa, como el pueblo de Bouglainval, se encuentra a pocos kilómetros de la capital del país, en este caso Barcelona. 
París, tot i fer-s'hi cada dia més cara la vida, tot i renegarne sovint perquè hi visc en constant agitació, se $m$ 'ha arrapat al cor. Sabria passar-me'n ${ }^{15}$ ?

[París, pese a que la vida cada vez se hace más cara, pese a renegar a menudo de ella porque vivo en permanente agitación, se me ha ligado al corazón. ¿Sabría pasar sin ella ?]

Ferran Canyameres se siente exiliado y tiene constantemente en la cabeza la idea del retorno. Tanto en el Diari íntim como en el epistolario hay numerosas referencias al tema, con los tópicos más característicos: la añoranza de la tierra, de la familia, el deseo de pasar las Navidades en casa, el pesimismo por la situación en el interior, etc. ${ }^{16}$ Sorprende, sin embargo, que cambie tantas veces de opinión sobre el momento propicio para el retorno. Ya durante el año 1942, por ejemplo, insinúa diversas veces en el dietario la posibilidad de regresar y, por lo que expresa el 18 de mayo de 1944 en carta a Pere Ballbé, parece que la repatriación ha de ser inmediata. Incluso afirma en ella que está haciendo el equipaje. La decisión quizás esté forzada por las circunstancias : son los momentos de los combates más duros en los alrededores de Bouglainval. Con el retorno a París pocos meses después y el final de la ocupación alemana, la decisión se aplaza y las dudas aumentan. Así, el 17 de mayo, en la carta ya citada, puede afirmar que está medio dispuesto a repatriarse y en cambio, sólo cinco días más tarde, comunica a Aurora Bertrana que "no tinc pas ganes de tornar a Barcelona" ["No tengo ganas de volver a Barcelona"]. El dilema es habitual en situaciones semejantes, pero en este caso concreto parece evidente que se añade una motivación extraordinaria : la atracción hacia París. Como hemos visto, buena parte de las referencias a la posibilidad de volver van asociadas al elogio de la capital francesa. Y, aún en 1949, tres meses antes del establecimiento definitivo en Barcelona, Canyameres confiesa al pintor Josep Picó - y en términos bien elocuentes - que el traslado es puramente provisional :

\footnotetext{
${ }^{15}$ Las dos últimas citas corresponden a una carta de 17 de mayo de 1948 , también a Mas $\mathrm{i}$ Perera.

${ }^{16}$ Son tópicos que reproduce en su obra literaria, especialmente en la poesía. Véase, por ejemplo, "Els corbs de l'exili" o "Cel baix", dos composiciones de Poesia secreta (1955) escritas en estos instantes.
} 
Anar-hi per quedar-m'hi? [a Barcelona] Ni pensar-hi. Quan la dona i la nena hi seran, procuraré fer-hi viatges de tant en tant, però el meu objectiu no és pas establir-m'hi. Miau! Ja veig com les gasten. A més, a mi em cal París. Si no pogués tornar a París em sembla que em passaria el mateix que li passa a l'esposa lluny de la seva terra, de la família, de la nostra casa ${ }^{17}$.

[¿Ir alli para quedarme? Ni pensarlo. Cuando la mujer y la niña estén alli, procuraré hacer viajes de vez en cuando, pero mi objectivo no es establecerme en la ciudad. ¡Miau ! Ya veo como las gastan. Además, a mí me hace falta París. Si no pudiese volver a París me parece que me pasaría lo mismo que le pasa a la esposa lejos de su tierra, de la familia, de nuestra casa.]

Existe todavía otro elemento a tener en cuenta para situar convenientemente el dilema. De hecho estamos ante un escritor y un intelectual que ansía poder desarrollar sus actividades en el marco de una cierta normalidad, lo cual durante los años cuarenta le es del todo imposible, tanto en el interior de su país como en el exterior. Muchas de las reflexiones sobre el exilio van es esa dirección. En 1944, todavía sin conocer el desenlace final de la guerra, ya duda respecto al lugar donde podrá desplegar mejor sus planes culturales, pero la situación le obliga a optar por el exilio. Lo afirma explícitamente en la carta a Pere Ballbé de 18 de mayo de 1944 :

Haig de dir-te, però, que si els mitjans econòmics m'ho permetessin, no passaria la frontera fins que la guerra s'acabés, fins que pogués tomar a casa després d'un canvi de règim allà baix que m'evitaria moltes humiliacions, que em permetria d'anar-hi a desplegar les meves activitats amb més embranzida.

[Debo decirte, sin embargo, que si los medios económicos me lo permitieran, no pasaría la frontera hasta que la guerra acabara, hasta que pudiera volver a casa después de un cambio de régimen allí abajo que me evitaría muchas

\footnotetext{
${ }^{17}$ La carta es de 19 de abril de 1949. El retorno se produce durante el mes de julio. Anteriormente, durante 1948, había realizado una corta estancia de tanteo en Barcelona para calibrar la situación. Es cierto que, desde julio de 1949, viaja diversas veces a Francia, pero su residencia real estará ya en Barcelona.
} 
humillaciones, que me permitiria ir a desarrollar mis actividades con más brío.]

En 1949 las circunstancias ya son diferentes a las de 1944 y, con la ligera adaptación del régimen franquista a la nueva situación motivada por el desenlace de la guerra mundial, la resistencia en el exilio padece un primer síntoma de debilitamiento. La balanza se decanta y Canyameres, que pese a haber militado en Esquerra Republicana de Catalunya (ERC) tampoco ha sido nunca un activista político, cree que desde el interior podrá llevar a mejor término los proyectos que tiene entre $\operatorname{manos}^{18}$.

\section{Los contactos entre exiliados catalanes en Francia}

Ha quedado claro cómo en diversas ocasiones el mismo Ferran Canyameres asocia París a un activismo frenético. El vitalismo inherente al escritor, las inmensas posibilidades de la ciudad y el hecho de que coincidan en ella en aquel momento diversos amigos exiliados facilitan que Canyameres se convierta en el aglutinador de numerosas actividades literarias relacionadas con el exilio catalán en la capital francesa. Hay momentos en los que él mismo cuestiona sus aptitudes como escritor, pero no su capacidad vital para la acción :

Dubtava de les meves condicions literàries, però mai del meu esperit emprenedor, amb el qual havia aconseguit tot allò que m'havia proposat. [...] Amb les meves accions, la cosa és molt diferent. Quan em desboco no hi ha aturador possible. Haig d'arremetre a fons fins a fer-me mal jo mateix. Després no hi

\footnotetext{
${ }^{18}$ Esto será cierto, en parte, pero no olvidemos que, con posterioridad al regreso definitivo, el escritor acaba conociendo el rigor de las prisiones franquistas. Concretamente, en junio de 1954 es detenido por auxilio a la rebelión armada debido a la ayuda humanitaria que había prestado a Joan Comorera, que entonces era secretario general del PSUC en la clandestinidad. Fue puesto en libertad en junio de 1955, pero su salud quedó seriamente afectada.
} 
ha manera de recular, $i$ menys encara quan es tracta d'una qüestió vital. ${ }^{19}$

[Dudaba de mis condiciones literarias, pero nunca de mi espíritu emprendedor, con el que había conseguido todo aquello que me había propuesto. [...] Con mis acciones, la cosa es muy diferente. Cuando me desboco no hay quien me pare. Tengo que arremeter a fondo hasta dañarme yo mismo. Después no hay forma de retroceder, y menos aún cuando se trata de una cuestión vital.]

Ferran Canyameres quedará vinculado de una u otra manera a buena parte de las iniciativas del exilio catalán en París : la reanudación de Revista de Catalunya, la creación de la asociación Cultura Catalana (de la que es consejero) o el intento de recuperar la "Fundació Ramon Llull". El dietario y el epistolario ofrecen poca información sobre estas actuaciones ${ }^{20}$. En cambio, sí que se explaya a propósito de la organización de los "Jocs Florals" de París del año 1948, en los que Canyameres actúa como secretario. Disponemos de una extensa carta de 19 de diciembre de 1948 dirigida al amigo Pere Mas i Perera - su principal confidente durante los últimos años del exilio -, en la cual explica hasta el último detalle su versión de la polémica generada durante el certamen, a causa básicamente del enfrentamiento entre facciones de ERC y del Partit Socialista Unificat de Catalunya (PSUC). Se trata de un documento fundamental para el estudio de los juegos florales como plataforma de la literatura catalana en el exilio. Es significativo también que Canyameres sea el responsable de la edición de un libro como Ofrena a Paris (1948), una antología de textos para la que, en un verdadero afán aglutinador, "puc avançar que hi figuraran tots els escriptors $i$ artistes catalans residents a França" ["puedo avanzar que figurarán en ella todos los escritores y artistas residentes en Francia ${ }^{21 "] .}$

Son así mismo interesantes las relaciones personales con los demás intelectuales - básicamente escritores - exiliados en París, que pasan

\footnotetext{
${ }^{19}$ CANYAMERES, Diari intim, op. cit., p. 248. Sebastià Gasch, en carta de 3 de agosto de 1941, reconoce también esta virtud del amigo: "M'admira la teva serenitat incolltorçable $i$ la teva enlluernadora capacitat de treball" ["Me admira tu serenidad inquebrantable y tu deslumbrante capacidad de trabajo"].

${ }^{20}$ Véase, por ejemplo, la carta a Mas i Perera de 17 de mayo de 1948.

${ }^{21}$ Carta de 28 de junio de 1945 a Feliu Elias.
} 
fugazmente por la ciudad o que vuelven a Cataluña después de haber residido en la capital una temporada. En algunas ocasiones los contactos son muy superficiales (con Armand Obiols o con Josep Carner) ${ }^{22}$, pero en otras la relación es bastante intensa, tal como demuestra la correspondencia conservada. Cabe destacar los ejemplos de Just Cabot, Pere Vigués, Melcior Font, Josep M. Millàs-Raurell o el pintor Antoni Clavé $\mathrm{y}$, muy especialmente, la rica correspondencia con Rafael Tasis y Sebastià Gasch. En la mayoría de estos casos, Canyameres actúa generosamente como valedor de sus compañeros y los ayuda a salir de la difícil situación económica en la que se encuentran muchos de ellos, sobre todo en los primeros tiempos. Sebastià Gasch es el principal interlocutor parisino de Canyameres hasta su retorno a Cataluña en 1942. A través del epistolario y de la narración "L'home que volia patir", escrita durante el mismo año 1942, podemos reconstruir muy bien las penurias del amigo $\mathrm{y}$, posteriormente, sus vicisitudes una vez ya en Barcelona. Después Rafael Tasis - una persona también muy activa en estos años - "omple el buit que ha deixat Sebastià Gasch" ["llena el vacío que ha dejado Sebastià Gasch" ${ }^{23 "] . ~ T a s i s ~ r e t o r n a ~ a ~}$ Cataluña a mediados de 1948, lo cual seguramente influye en la decisión final del escritor terrasense de emprender también el camino de regreso.

Pero los contactos de Ferran Canyameres con el exilio catalán en Francia no se limitan únicamente al mundo parisino. A través de su correspondencia podemos reconstruir el tejido de relaciones entre los diferentes grupos repartidos por el país. Son especialmente interesantes los vínculos con la zona de Tolosa a través de su amigo Lluís Capdevila (que vive en Ax-les-Thermes, pero escribe también alguna vez desde Tolosa), Àngel Ferran o Alfons Serra i Baldó (ambos en Tolosa), Salvador Perarnau (en Ax-les-Thermes) y Joan Baptista Xuriguera (en Montauban). En este sentido, cabe destacar la victoria de Canyameres en 1948 en el "Premi de Teatre Català de Tolosa de Llenguadoc" con El cercle de la por (1957), obra que fue estrenada el mismo 1948 tanto en Tolosa como en París.

${ }^{22}$ Para el caso de Josep Carner, véase Marcel ORTÍN (ed.), "Epistolari entre Josep Carner i Ferran Canyameres", en Albert MANENT, Jaume MEDINA (eds.), Epistolari de Josep Carner (volumen III), Barcelona, Curial, 1997, p. 17-34.

${ }^{23}$ Carta a Pere Vigués de 27 de enero de 1943. Sobre la relación entre ellos dos véase Sebastià GASCH, "El Ferran Canyameres que he conegut (commemoració del centenari)", Revista de Catalunya, 127 (marzo 1998), p. 9-40; y Rafael TASIS, "Ferran Canyameres", Serra d'Or, VI, 11 (diciembre 1964), p. 85-88, nota escrita con motivo del fallecimiento del amigo. 
Precisamente Lluís Capdevila - que había dado consejos a Canyameres sobre los retoques que podía hacer a la obra antes de presentarla - gana el segundo premio, cosa que enrarece un poco la relación entre ambos ${ }^{24}$. Otro de los núcleos de contacto es el entorno de Prada de Conflent, con Pau Casals, Joan Alavedra, Julià Gual $\mathrm{y}$, sobre todo, Aurora Bertrana. Canyameres viaja allí en alguna ocasión. También mantiene relación, como mínimo, con Eugeni Xammar y Antoni Rovira i Virgili en Perpiñán, Josep M. Lladó y el grupo de la revista Per Catalunya en Niza o Humbert Torres y Miquel Guinart en Montpellier, ciudad que organiza los "Jocs Florals de la Llengua Catalana" de 1946. Precisamente uno de los galardones del cartel es ofrecido por Canyameres, concretamente el premio al mejor trabajo sobre el arte del libro catalán.

Vale la pena señalar que esta proliferación de contactos entre exiliados en Francia contrasta con la casi nula relación con la resistencia cultural en el interior o con el exilio americano. El único vículo con América es a través de Pere Mas i Perera en Buenos Aires, y el diálogo ofrece muy poca información sobre los grupos catalanes que han acabado asentándose más allá del Atlántico. Los canales de comunicación no eran siempre fáciles, pero tampoco se observa una excesiva voluntad de establecerlos. El exilio francés - y en esto no es una excepción - vive en un cierto aislamiento interno y la trayectoria de Ferran Canyameres ayuda a corroborarlo.

\section{Una muestra del vitalismo emprendedor : la Editorial Albor}

La creación en 1943 de la Editorial Albor en París es la actividad más importante de Ferran Canyameres en estos años y una de las principales iniciativas del exilio literario catalán ${ }^{25}$. La idea surge a mediados de 1942 tras una primera visita a Georges Simenon y la intención inicial es publicar traducciones del novelista belga, razón por la cual el futuro editor firma un convenio con Pere Ballbé, que es quien da soporte económico a la iniciati-

\footnotetext{
${ }^{24}$ Sobre esta cuestión, véanse las cartas cruzadas con Àngel Ferran del 15 y 24 de febrero de 1948.

${ }^{25}$ Véase Albert MANENT, La literatura catalana a l'exili, Barcelona, Curial, 1976.
} 
$\mathrm{va}^{26}$. Canyameres deja claro en el momento de la gestación de la empresa que, además de Simenon, lo que quiere es "publicar tota classe de llibres" ["publicar toda clase de libros"]. Y añade : "considero que l'edició de llibres catalans a Paris ha d'enfocar-se de manera que ningú no es cregui que es tracta d'afavorir un determinat sector" ["considero que la edición de libros catalanes en París debe enfocarse de manera que nadie crea que se trata de favorecer un determinado sector ${ }^{27}$ "]. Las circunstancias - principalmente la escasez de papel durante la guerra - obligan a restringir los objetivos iniciales y a limitarse a las ediciones de bibliófilo, con tiradas que oscilan entre los 50 y los 250 ejemplares ${ }^{28}$. En total se publican siete volúmenes entre 1943 y 1949 : Tot l'any (1943), una glosa de las fiestas tradicionales escrita por Rafael Tasis, con ilustraciones de Antoni Clavé ; Paisatges (1944), con poemas de autores diversos, prólogo de Feliu Elias y litografías de Martí Bas ; Claror de nit (1945) de Ferran Canyameres, con ilustraciones del mismo Martí Bas ; XIV cançons populars catalanes (1946), con prólogo de Josep Carner y puntas secas de Joan Rebull ; Dos contes (1947) de Ramon Reventós, con aguafuertes de Picasso ; Ofrena a París dels intel.lectuals catalans a l'exili (1948), con textos de numerosos autores, frontispicio de Pablo Picasso y 35 dibujos a la pluma de diferentes artistas ; y Barcelona a vol d'infant (1949) de Ferran Canyameres, con litografías en color de Emili Grau Sala.

Esta primera etapa en París de Editorial Albor constituye una actividad ambiciosa, que ofrece resultados brillantes y que puede llegar a buen puerto gracias al voluntarismo y pese a disponer de pocos medios materiales. A través de esta correspondencia podemos reconstruir bastante bien la historia y las vicisitudes de la aventura. Lo que descubrimos sobre todo es la enorme tenacidad de Canyameres para hacer funcionar la empresa. Las fechas de

\footnotetext{
${ }^{26}$ Véase la carta de 13 de diciembre de 1942 a Pere Vigués. Pere Ballbé y su hermano Marià eran fabricantes terrasenses del textil y estaban ya instalados en París cuando los exiliados de 1939 llegaron a la ciudad.

${ }^{27}$ Las dos citas corresponden a la carta de 28 de julio de 1943, dirigida a Rafael Tasis. Tres días antes, en carta a Just Cabot, reproduce los aspectos fundamentales del convenio y los primeros proyectos en curso.

28 "I fer edicions corrents, ni pensar-hi. És més facil trobar paper bo que ordinari" ["Y hacer ediciones corrientes, ni pensarlo. Es más fácil encontrar papel bueno que ordinario"] comenta a los hermanos Ignasi y Lluís Vidal i Molné en carta de 6 de junio de 1945. Hay momentos en los que incluso debe reducir la tirada prevista porque no puede comprar papel ni en el mercado negro.
} 
publicación - un libro al año - hacen intuir un ritmo de edición regular y un funcionamiento metódico. La realidad, sin embargo, es bien distinta. Se quedan en el tintero otros volúmenes frustrados (de Just Cabot, Feliu Elias, Joan Maragall, el mismo Canyameres, Eugeni Xammar, Josep Pous i Pagès, Màrius Torres, etc). Sobre algunos de estos libros se ofrecen detalles que hacen pensar que los proyectos estaban ya muy avanzados. Éste es el caso, por ejemplo, de los poemas inéditos de Màrius Torres o de las narraciones de Tota la saviesa d'aquest món de Pous i Pagès ${ }^{29}$.

Pero no es sólo esto. La historia de algunos de los libros que finalmente se publican también es curiosa y compleja. Hay casos en los que el proceso de producción se alarga durante años a causa de los inacabables retrasos de los colaboradores, muchos de los cuales habían cobrado por adelantado. El libro de Ramon Reventós, por ejemplo, está a punto de malograrse - pese al interés de Picasso por el proyecto - simplemente porque Canyameres tiene problemas para encontrar a alguien en el interior que haga el esfuerzo de recopilar los dos cuentos. La correspondencia también permite leer una agria polémica con Emili Grau Sala sobre las litografias de Barcelona a vol $d^{\prime}$ infant $^{30}$ o demuestra que la edición de $X I V$ cançons populars catalanes está detenida más de un año porque Just Cabot no termina nunca de redactar una introducción que no tiene que ocupar más de una página y media. Así se lo comunica el editor a Feliu Elias el 31 de julio de $1945^{31}$. Toda la carta constituye, de hecho, un curioso memorial de agravios que sintetiza buena parte de los problemas existentes y que acaba con una frase bien clarificadora :

${ }^{29}$ Humbert Torres habla con el editor el 12 de octubre de 1947 de la posibilidad de que el libro póstumo de poesía de su hijo aparezca por Navidad e incluso entra en detalles sobre la corrección de pruebas. El volumen se publica finalmente con fecha del mismo año 1947, pero a través de Joan Sales y en México. Respecto a las narraciones de Pous i Pagès, que tenian que ir acompañadas con dibujos de Feliu Elias, Canyameres confiesa al ilustrador el 31 de julio de 1945 que todo está a punto pero que el proceso de impresión está detenido por falta de papel. Tota la saviesa d'aquest món no aparecerá hasta 1962 y en una edición que no tiene nada que ver con la de 1945.

${ }^{30}$ CANYAMERES, Epistolari, op. cit. p. 157-158. El libro sale de la imprenta en septiembre de 1943, pero no se publica hasta 1949, básicamente por culpa de los sucesivos retrasos del ilustrador.

${ }^{31}$ El libro aparece finalmente en 1946, pero con prólogo de Josep Carner. 
Com podeu veure, n'hi ha per posar-s'hi malalt, per engegarho tot enlaire. És importantíssim el capital que tenim invertit en aquestes edicions, car tot està pagat, àdhuc molts treballs que alguns encara han de començar. Els unics que han complert sou vós $i$ Marti Bas. Els altres ens han fet patir, suar i renegar amb llur lentitud, per no dir amb llur incomprensió o manca d'amor propi. El nostre gust seria, malgrat tot, adquirir els drets d'altres obres que guardariem per Barcelona si no fos possible publicar-les aqui. Però mentre no hàgim desencallat el carro [...] no estarem en condicions de fer més despeses.

[Como puede ver, es para caer enfermo, para mandarlo todo a paseo. Es importantísimo el capital que tenemos invertido en estas ediciones, ya que todo está pagado, incluso muchos trabajos que algunos aún tienen que empezar. Los únicos que han cumplido son usted y Martí Bas. Los demás nos han hecho padecer, sudar y renegar con su lentitud, por no decir con su incomprensión o falta de amor propio. Nuestro deseo sería, a pesar de todo, adquirir los derechos de otras obras que guardaríamos para Barcelona si no fuese posible publicarlas aquí. Pero mientras no hayamos desencallado el carro [...] no estaremos en condiciones de hacer más gastos.]

Recordemos que la voluntad inicial no era publicar tan sólo ediciones de bibliófilo. Canyameres no lo logra, pero no precisamente por falta de interés. $\mathrm{Su}$ deseo es que una editorial francesa, concretamente Éditions Universelles - la que había publicado en francés la biografia de Josep Oller -, cree una colección en lengua catalana que también se llamaría Albor : "Considero que és únicament per mitjà d'una editorial francesa que es pot difondre arren la nostra literatura amb edicions corrents" ["considero que es únicamente a través de una editorial francesa que se puede difundir en todas partes nuestra literatura con ediciones corrientes"], comunica el 20 de junio de 1946 a Lluís Capdevila. El típico vigor con que el escritor terrasense afronta este tipo de iniciativas hace pensar que el proyecto se encuentra en una fase avanzada. El editor francés da inicialmente la conformidad y Canyameres pide originales a numerosos autores, entre ellos Feliu Elias (a quien encarga un libro sobre Picasso y otro dedicado a cuestiones de arte), Diego Ruiz (quiere publicarle El que la humanitat deu a Catalunya), Josep Carner, Lluís Capdevila, Antoni Rovira i Virgili, Aurora Bertrana y Amadeu 
Hurtado $^{32}$. Canyameres trabaja con insistencia en el tema desde mediados de 1946, pero tiene que acabar renunciando. El 4 de enero de 1948 ya tiene serias dudas de que la idea salga adelante. Así lo hace saber a Lluís Capdevila :

Fa temps que observo que M. Àngel [el editor francés] va de bòlit. Fa tres mesos que em diu que sortirà el primer volum de la Col lecció Catalana i el més calent és a l'aiguera. És precisament darrera l'aigüera del seu piset-despatx on guarda els manuscrits. Quant al catàleg, passa el mateix. Ja no sé què dir ni què fer.

[Hace tiempo que observo que M. Angel [el editor francés] anda de cabeza. Hace tres meses que me dice que saldrá el primer volumen de la colección catalana y todo está aún por hacer. Es precisamente detrás del fregadero ${ }^{33}$ de su pisodespacho donde guarda los manuscritos. Con respecto al catálogo, pasa lo mismo. Ya no sé qué decir ni qué hacer.]

Está de por medio, además, el tema de las traducciones de Simenon, que nunca queda del todo aparcado. Canyameres obtiene del novelista belga los derechos para la publicación de sus obras en castellano, por lo que inicia enseguida las gestiones para sacar adelante el proyecto ${ }^{34}$. Se da cuenta perfectamente de que la operación es de calado e inviable desde el exilio, por lo que procura contactar a través de intermediarios con alguna editorial barcelonesa para que se responsabilice de la empresa. Mediante el Diari intim - y sobre todo a través del epistolario - podemos ir siguiendo las gestiones: los tratos con Sebastià Gasch y Carles Soldevila como intermediarios, las negociaciones con Editorial Juventud y después con Aymà, el diálogo directo con Simenon, su dedicación intensiva a la

${ }^{32}$ Incluso quedan establecidas las condiciones de los acuerdos: $10 \%$ para el autor, 2500 ejemplares y la posibilidad de una edición en francés, la cual generaría necesariamente la firma de un nuevo contrato.

${ }^{33}$ La referencia al fregadero proviene de la expresión catalana "el més calent és a l'aigüera", que debemos traducir por "todo está aún por hacer", pero que literalmente significa "lo más caliente está aún en el fregadero".

${ }^{34}$ Josep M. Poblet relata las circunstancias que, según él, motivaron la firma de un contrato beneficioso para Canyameres, pero su versión - con un toque un poco novelesco - parece poco fiable (Josep M. POBLET, Símbol vivent. Biografia de Rafael Tasis, Barcelona, Editorial Arimany, 1967, p. 122-123). 
traducción, el encargo de otras traducciones a Rafael Tasis y Just Cabot que Canyameres paga de su bolsillo por adelantado -, las presiones de diversas editoriales españolas que quieren hacerse con los derechos, etc. Tambiẻn en este proceso hay que superar numerosos obstáculos. Pensemos que la primera traducción, Los crímenes del canal, no aparece publicada hasta diciembre de 1948 (finalmente en Aymà) y que los contactos iniciales se remontan al año 1942. Canyameres consigue de manera casi milagrosa mantener la confianza de Simenon - que seguramente era un hombre paciente -, lo cual no le resulta nada fácil. Tiene que convencerlo incluso de la conveniencia de prorrogar el contrato inicial, el cual era solamente para dos años. Algunas de las cartas del belga son ultimátums en firme y las respuestas del interlocutor se convierten en auténticas antologías de la autojustificación ${ }^{35}$. El 30 de marzo de 1947 Canyameres resume todo este proceso en una carta a Pere Mas i Perera :

L'any 1942 vaig comprar els drets de traducció $i$ d'edició en castellà, a Espanya, de totes les obres del cèlebre novel.lista belga Georges Simenon, amb el qual m'uneix una bona amistat. Malgrat que són a dotzenes les cases editorials espanyoles que s'adrecen a ell per comprar-los, diu a tothom que sóc jo qui ha de decidir [...]. No obstant, el temps passa $i$ temo que Simenon es cansi d'esperar el meu retorn a Barcelona $i$ m'obligui a editar a Espanya o a rescindir el contracte, la qual cosa m'ocasionaria un gran perjudici. Per ara l'aguanto dient-li que la pesseta se'n va al carall, que la censura li mutilaria els textos, etc. No sé pas com m'ha tingut tanta consideració.

[En el año 1942 compré los derechos de traducción y de edición en castellano, para España, de todas las obras del célebre novelista belga Georges Simenon, con el que me une una buena amistad. Pese a que son por docenas las casas editoriales españolas que se dirigen a él para comprarlos, dice a todo el mundo que soy yo quien debe decidir [...]. No obstante, el tiempo pasa y temo que Simenon se canse de

${ }^{35}$ Véase especialmente la carta de Simenon de 20 de marzo de 1945, en la que habla incluso de presiones del ministerio francés de Asuntos Exteriores; y una de les contestaciones de Canyameres (la del 20 de enero de 1948), en la cual resume todos los quebraderos de cabeza que tiene que ir solucionando y acaba con un "Laissez-moi faire. Encore un peu de pacience [sic]. Je vous promets que vous n'aurez pas à regretter votre confiance". 
esperar mi retorno a Barcelona y me obligue a editar en España o a rescindir el contrato, lo cual me ocasionaría un gran perjuicio. Por ahora lo aguanto diciéndole que la peseta se va al carajo, que la censura le mutilaría los textos, etc. No sé cómo me ha tenido tanta consideración.]

Ciertamente, tal como insinúa la cita anterior, el proyecto Simenon difícil de coordinar desde París - es una de las causas principales del retorno del escritor a Barcelona en 1949. Una vez más se demuestra, pues, que las conexiones entre el exilio y el interior son poco fluídas y Canyameres padece personalmente las consecuencias de ello. Se evidencia también que, a finales de los cuarenta, la lucha por la normalidad cultural - por muy precaria que sea - empieza a ser más efectiva desde dentro que desde fuera. Ya en Barcelona, la operación se agiliza y las traducciones de Simenon pese a algunos problemas de censura - van apareciendo con regularidad, hasta 1954 con pie de imprenta de Aymà y después nuevamente con el histórico sello de Editorial Albor.

\section{Apunte final : un perfil completo}

Para acabar de perfilar la imagen de la trayectoria intelectual de Ferran Canyameres durante los años del exilio francés deben tenerse en cuenta otros elementos. Uno de ellos, ciertamente, lo tenemos en el trabajo de estricta creación literaria ${ }^{36}$. Entre 1939 y 1949 Canyameres publica la novela corta Claror de nit (1945), las impresiones de Barcelona a vol d'infant (1949), la biografia en francés de Josep Oller (L'homme de la belle époque, 1946) y estrena la pieza teatral El cercle de la por (1948). Estos textos, sin embargo, son sólo una pequeña parte de lo que escribe. Se trata de un periodo de gran producción literaria, especialmente durante la estancia en Bouglainval. Por lo que sabemos, especialmente a través de lo que dice en su diario íntimo, durante el exilio deja prácticamente acabados un número considerable de aquellos libros que publicará posteriormente, además de un montón de

${ }^{36}$ Para el análisis intrínseco de las obras, véanse principalmente los diversos artículos del monográfico sobre Canyameres publicado por la revista Ciutat de Terrassa (7, primavera 1998): Magda ALEMANY, "L'obra narrativa de Ferran Canyameres" (p. 22-25); Jordi LLAVINA, "La poesia de Ferran Canyameres" (p. 26-29); Lluís SERRASOLSES, "L'obra autobiogràfica de Canyameres" (p. 30-34); Lluís SERRASOLSES, "L'obra dramàtica de Ferran Canyameres" (p. 35-36). 
material que quedará inédito. Lo compagina con la traducción de Simenon : "Jo intercalo la traducció posant al paper tot el que em balla pel cap i m'ha fet ballar" ["yo intercalo la traducción poniendo en el papel todo lo que me pasa por la cabeza y me ha pasado"], afirma a Pere Vigués el día 11 de enero de 1943. Pocos días antes (el 13 de diciembre de 1942) ya le había comentado que tenía terminado un libro de cuentos, además de "moltes altres coses sobre viatges, dues novel les i què se jo! A vegades penso que potser tot serà feina inútil" ["muchas otras cosas sobre viajes, dos novelas y ¡qué sé yo !]. En alguna ocasión el mismo Canyameres se burla de su propia fiebre creadora compulsiva, que él asocia bastante a las circunstancias del exilio. Fijémonos en esta reflexión antológica, extraída de la carta a Just Cabot de 27 de enero de 1943 :

Quan els exiliats tornarem al nostre pais n'hi haurà un tip de tanta literatura. El millor que es podria fer seria condemnar cada autor a la lectura de tot el que s'ha escrit durant els quatre anys (o els que siguin, car sembla que va per llarg) $[\ldots .$.$] , deixant en pau els lectors en general que no hi tenen cap$ culpa.

[Cuando los exiliados volvamos a nuestro país estaremos hasta la coronilla de tanta literatura. Lo mejor que se podría hacer es condenar a cada autor a la lectura de todo lo que ha escrito durante los cuatro años (o los que sean, porque parece que va para largo) [...], dejando en paz a los lectores en general que no tienen culpa alguna.]

Una parte importante de la obra poética es también de estos años. El estado de ánimo en el que se encuentra durante los episodios más duros de la guerra vividos en Bouglainval facilitan la dedicación al género. De este modo lo explica a Feliu Elias en la carta de 31 de julio de 1945 :

Vaig posarme a versificar els darrers mesos de la meva residència en un poblet de l'Eure et Loir, des d'on us havia escrit alguna vegada. En la impossibilitat de restar una hora seguida assegut davant d'una taula a causa dels terribles bombardeigs que assolaven aquella contrada, entre raid $i$ raid d'avions, arran de boca d'una trinxera cavada a l'ombra 
d'un pomerar, era amb la poesia que trempava els meus nervis o que distreia la por ${ }^{37}$.

[Me puse a versificar durante los últimos meses de mi residencia en un pueblecito del Eure et Loir, desde donde le había escrito alguna vez. Ante la imposibilidad de permanecer una hora seguida sentado frente a una mesa a causa de los terribles bombardeos que asolaban aquella zona, entre ataque $\mathrm{y}$ ataque de aviones, junto a la boca de una trinchera cavada en la sombra de un manzano, era con la poesía con lo que templaba mis nervios o distraía el miedo.]

$Y$ añade :

Ja ha passat. No crec que m'atreveixi gaire més a refugiarme, insegur, en la rima tonificadora.

[Ya ha pasado. No creo que me atreva mucho más a refugiarme, inseguro, en la rima tonificante.]

Éste es un buen ejemplo de cómo la poesía es una dedicación que el mismo autor considera más bien circunstancial y que entiende básicamente ligada a los tiempos de guerra y exilio.

Pero en estos años Ferran Canyameres no es solamente un escritor infatigable, sino también un lector voraz ${ }^{38}$ - sobre todo de literatura francesa - y un gran aficionado al cine. A través del dietario podemos acercarnos a estas otras actividades, las cuales acaban de completar el perfil intelectual y vital de un auténtico hombre de letras.

37 Véase igualmente la introducción del autor a Com el Vallès no hi ha res (1951), en CANYAMERES, Obra completa (volum III), op. cit., p. 39-40. Joan Oliver, en el prólogo a Migtemps (1950), también afirma que "els poemes que conté el present volum han estat triats d'una copiosa producció lírica, esdevinguda en un periode que no arriba als tres anys (1944-1947)" ["Los poemas que contiene el presente volumen han sido escogidos de entre una copiosa producción lírica, realizada en un periodo que no llega a los tres años (19441947)"] (Ibid., p. 6).

38 En el Diari intim hace mención a los "llibres que devoro per evadir-me del neguit ambiental" ["libros que devoro para evadirme de la ansiedad ambiental"] (op. cit., p. 557). 